\title{
Different material properties of cancellous bone influence analysis of glenoid component loosening: A finite element study
}

\author{
Abdul Hadi Abdul Wahab a, Mohammed Rafiq Abdul Kadir ${ }^{b,}{ }^{*}$, Muhammad Noor Harun ${ }^{b}$, \\ Ardiyansyah Syahrom ${ }^{b}$, Mohammad Hanif Ramlee ${ }^{\mathrm{a}, \mathrm{b}}$ \\ a Medical Devices Technology Group (MediTeg), Faculty of Biosciences and Medical Engineering, Universiti Teknologi Malaysia, Skudai 81310 , \\ Johor, Malaysia \\ b Sport Innovation and Technology Centre (SITC), Institute of Human Centered Engineering (IHCE), Universiti Teknologi Malaysia, 81310 UTM \\ Johor Bahru, Johor, Malaysia \\ *Corresponding author: rafiq@biomedical.utm.my
}

\section{Article history}

Received 15 October 2017

Accepted 11 December 2017

\begin{abstract}
Glenoid component loosening is one of common complications after total shoulder arthroplasty. In investigating the glenoid component loosening, the finite element study is one of methods that have been utilised by experts. Therefore, assigning material properties for all finite element models become crucial to avoid any misinterpretation which, later, lead to wrong prediction on the performance of glenoid implant. This study was conducted to achieve two objectives; (1) to analyse the effect of different bone properties towards micromotion and stress at implant and cement, and (2) to clarify simplification of bone properties in evaluating glenoid component loosening. A load of $750 \mathrm{~N}$ was simulated at three different glenoid locations (centre - C, superior-anterior-SA, superior-posterior-SP) which imitate concentric and eccentric loadings for elderly people daily activities. Our result showed that large different in micromotion and stress at implant between orthotropic model and another two model (isotropic and full cortical) does not allow simplification for assigning material properties for bone. Thus, assigning cancellous bone as orthotropic material was a realistic material property to represent the real bone condition in evaluating glenoid implant loosening.
\end{abstract}

Keywords: Bone properties, orthotropic, isotropic, shoulder, glenoid loosening

() 2017 Penerbit UTM Press. All rights reserved

\section{INTRODUCTION}

Glenoid component loosening is one of common complications after total shoulder arthroplasty. The occurrence rate of glenoid component loosening records between $14.3 \%$ to $59 \%$ (Armstrong, 2013; Bohsali, Wirth, \& Rockwood, 2006; Gonzalez, Alami, Baque, Walch, \& Boileau, 2011; Rodosky \& Bigliani, 1996). There were many factors caused glenoid component loosening and one of it was due to Rocking Horse Phenomena (RHP). It was initiate when the humeral head translate to off-centre region of glenoid, also known as eccentric loading, which induced high stress at the rim of the implant. This high stress caused glenoid implant tilting at the opposite site of load had been applied. Repetition of this activities, later, caused implant to rock. Consequently, lead to glenoid component loosening (Matsen, et al. 2008). In investigating the glenoid component loosening due to RHP, finite element (FE) analysis is one of the method had been utilised by an experts instead of experiment (Allred et al., 2016; D. M. Geraldes et al., 2017). When conducting FE analysis for assessing glenoid component loosening due to RHP, it was crucial to assign the suitable properties for bone, therefore, the outcomes of the analysis could represent the actual condition of scapula bone, then, lead to correct prediction for glenoid component. Furthermore, it can avoid any misinterpretation of results due to improper simplification had been made during assigning the material properties for bone. Scapula bone consists of the cancellous and cortical bone, where cancellous bone is an orthotropic material (Wirtz et al., 2003). In some previous studies, they simplified the cancellous bone by considering the whole scapula as a full solid cortical bone in their FE models (Yongpravat et al., 2013; J. Zhang et al., 2013). While, some studies dividing scapula into cortical and cancellous bone in two diferent cases. The first studies assumed the cancellous bone as isotropic material (Gupta et al., 2004; Yongpravat et al., 2013) and another case assigned it as orthotropic material (Abdul Wahab et al., 2016; Couteau et al., 2001; Wahab i, 2017). Based on the previous literature, there are no specific methods in assigning material of scapula which discussing the impact of different bone properties to assess glenoid implant loosening. Therefore, this study with an intention to investigate the aforementioned issue with two main objectives, (1) to analyse the effect of material properties of cancellous bone on performance of glenoid implant especially on micromotion at cement-bone interface, and stress at implant and cement (2) to clarify the simplification of bone properties for evaluating glenoid component loosening. In this study, three models had been analysed; the first model was assigned with full cortical where there is no cancellous bone, namely as Model 1). For another two models which consist of cortical and cancellous bone, but had different cancellous properties, which are Model 2 and Model 3. Figure 1 illustrated the different between the models. 


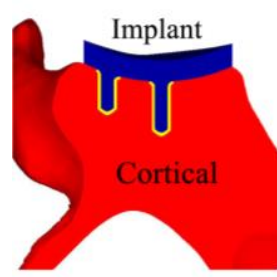

(a)

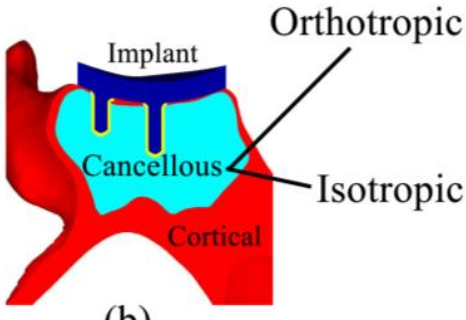

(b)
Figure $13 \mathrm{D}$ bone models (a) Model 1, (b) Model 2 and Model 3 with different material properties for cancellous.

\section{MATERIALS AND METHODS}

\section{Component Design}

Glenoid implant with four pegs and cement was modelled using three-dimensional computer-aided design (CAD) software (Dassault Systèmes SolidWorks Corp., USA). The material, shape, thickness and radius of curvature of implant were set to all-polyethylene, pear-shape, $4 \mathrm{~mm}$, and $29.5 \mathrm{~mm}$, respectively. The height, lower width, and upper width of the glenoid implant were measured from Malaysian glenoid bone CT dataset. For the lower width, upper width and height, of the implant, the measurement were $23.5 \mathrm{~mm}, 16.7 \mathrm{~mm}$, and $32 \mathrm{~mm}$ respectively. The length for peripheral and central peg were set to $10 \mathrm{~mm}$ and $14 \mathrm{~mm}$, respectively and both had $3 \mathrm{~mm}$ in diameter. The thickness of cement used was $0.5 \mathrm{~mm}$ (Terrier, Büchler, \& Farron, 2005).

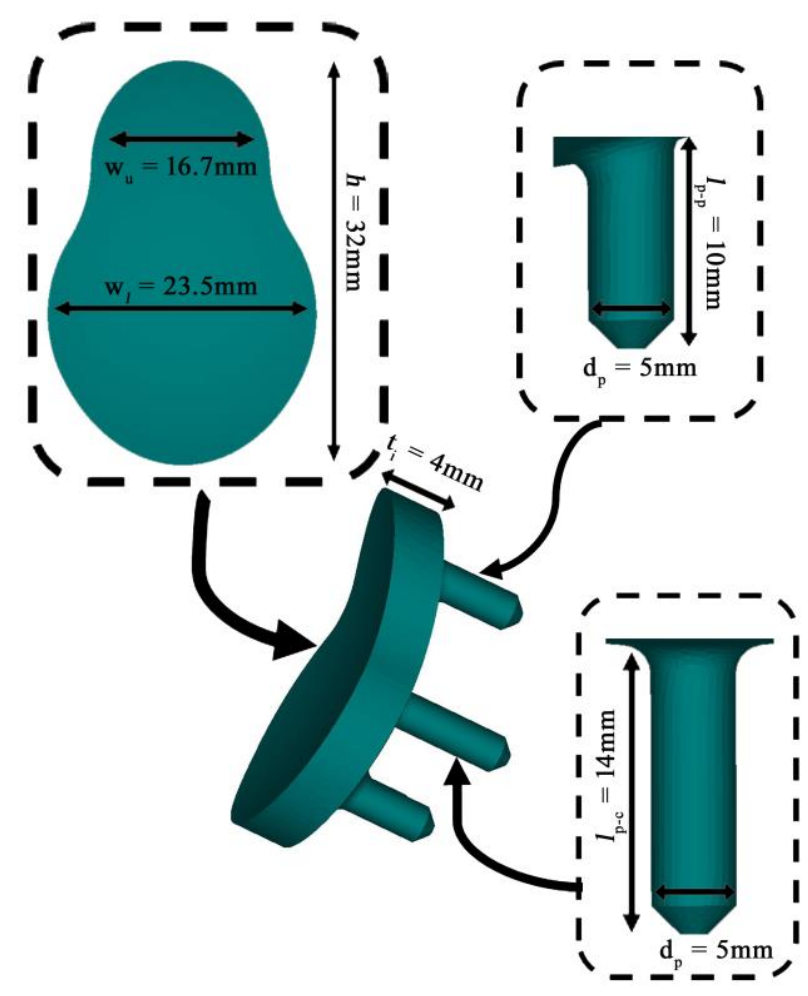

Figure 2 Dimension for glenoid implant

\section{Finıte tıement Ivıae}

The scapula cortical and cancellous bone 3D model were reconstructed from intact $\mathrm{CT}$ image data using commercial software (Mimics, Materialise, Leuven, Belgium). The axial slice thickness of CT dataset was $0.537 \mathrm{~mm}$. Hounsfield Unit (HU) values have been used to differentiate between cortical and cancellous where $\mathrm{HU}>350$ was set to cortical and as for cancellous bone was in between $120-350$. A convergence study was confirmed that the optimum number of elements and nodes for cortical bone were varies between 161,021 to 239,401 and 42,857 to 52,523 , respectively. While, for cancellous, the number of element was 66,012 and number of nodes was 18,024 . The number of elements for implant and cement were 50,361 and 69,465, respectively, and number of nodes were 12,694 and 14,924, respectively. All parts of bone and implant have been assigned with 4nodes tetrahedral elements. The prosthesis and cement were meshed in Abaqus, Inc. software, and the implant was positioned into bone via Mimics software. The prosthesis was fixed to the best fit position, with minimally resect of glenoid subchondral bone and optimally support (Jones, 2013). The final model was saved in STL file and MSC Marc Mentat (MSC Software, Santa Ana, USA) software was used for further finite element analysis. As for contact at the interfaces, fully bonded for implant-cement interfaces and not bonded for implant-bone and cement-bone interfaces were set accordingly. This can allows micromotion at the interfaces be assessed. The friction coefficient $(\mu)$, for not bonded interfaces were set to 0.6 (Terrier et al., 2005; Wahab et al., 2017). Mechanical parameters were considered that includes stress at implant, stress critical volume (SCV), which refers to volume of cement which exceed $5 \mathrm{MPa}$, and micromotion at cement-bone and implant-bone interfaces. On top of that, the time for analysis to be done have been recorded in order to compare the models..

\section{Material Properties}

The material properties for cortical bone was assigned with isotropic material for all three models, while, material properties for cancellous bone had been set as, isotropic, and orthrotropic.material for model 2 and model 3 as stated in table 1 . In model 1, cancellous bone was not considered, therefore, it was set as cortical properties for the whole scapula bone. For glenoid implant, the properties were set with a Young's modulus (E) of 965MPa and Poisson's ratio (v) of 0.34 . While, for PMMA cement, the Young's modulus (E) was set to 2000MPa, and Poisson's ratio (v) was set to 0.23 (P. Mansat et al., 2007).

Table 1 Material properties for three different models

\begin{tabular}{ll}
\hline Model & Material properties \\
\hline Model 1 & $\mathrm{E}_{\text {cort }}=16,000 \mathrm{MPa}$ \\
(Full Cortical) & $v_{\text {cort }}=0.3$
\end{tabular}

\begin{tabular}{|c|c|}
\hline $\begin{array}{l}\text { Model } 2 \\
\text { (Isotropic) }\end{array}$ & $\begin{array}{l}\frac{\text { Cortical }}{\mathrm{E}_{\text {cort }}=16,000 \mathrm{MPa} ; v_{\text {cort }}=0.3 ;} \\
\text { Cancellous }(Y o n g p r a v a t \text { et al., 2013) } \\
\mathrm{E}_{\text {can }}=574 \mathrm{MPa} ; v_{\text {can }}=0.3\end{array}$ \\
\hline $\begin{array}{l}\text { Model } 3 \\
\text { (Orthotropic) }\end{array}$ & 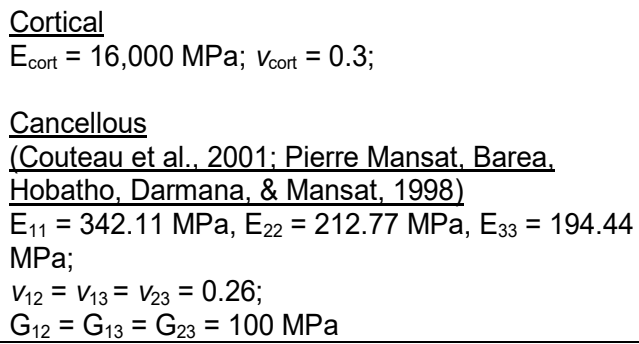 \\
\hline
\end{tabular}

\section{Boundary Conditions}

Boundary condition were set as in Figure 2. The medial border of scapula was fixed in all degree of freedom. As per axial load, $750 \mathrm{~N}$ load was applied at three different location, which are center (C), superior-anterior (SA), and superior-posterior (SP) and this value represent the daily activities done by elderly people such as sitting down to a chair, lifting a $5 \mathrm{~kg}$ suitcase, and walking with stick (Anglin, Wyss, Nyffeler, \& Gerber, 2001) 


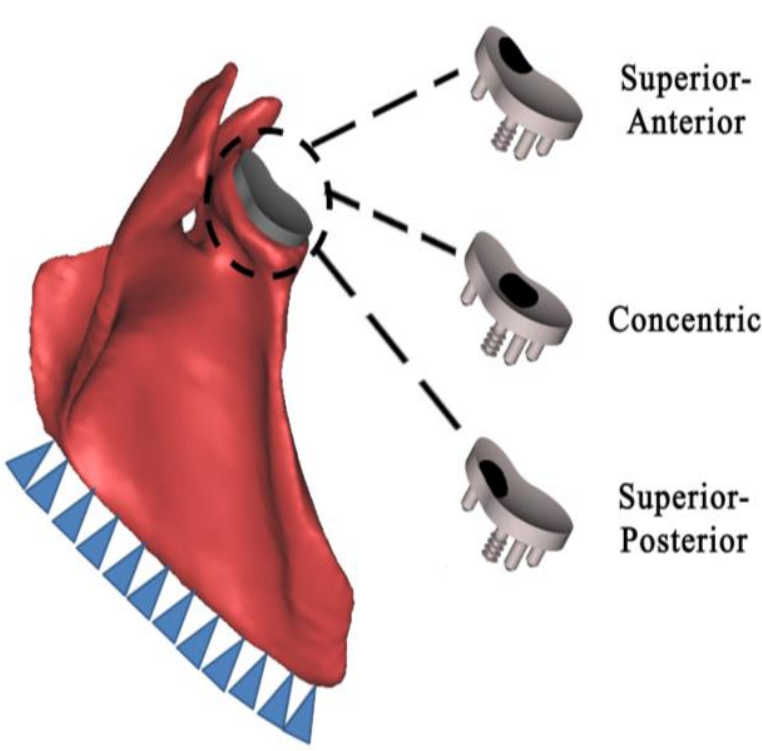

Figure 3 Boundary condition have been set for all three models

\section{RESULTS AND DISCUSSION}

Cancellous bone properties was already known as an orthotropic material (Baca et al., 2008; Diogo M. Geraldes \& Phillips, 2014; Miller, Fuchs, \& Arcan, 2002; Wirtz et al., 2003). In in silico study, assigning material properties is a fundamental step in creating finite element models of bone. Therefore, it is important to assign material properties which can mimics the real behaviour of human bone. Scapula bone be made of cancellous and cortical bone, where, cancellous bone was an orthotropic material (Wirtz et al., 2003). However, in some previous studies, the cancellous bone was neglected and considered scapula as a full solid cortical bone (Yongpravat et al., 2013). While, some studies dividing scapula bone into cortical and cancellous bone but some of the studies assumed the cancellous bone as isotropic material (Yongpravat et al., 2013), while, another assigned the cancellous as orthotropic material (Abdul Wahab et al., 2016; Couteau et al., 2001; Wahab et al., 2017). Thus, in this study, three type of bone properties, which are full cortical (model 1), isotropic (model 2), and orthotropic (model 3), were compared to analyse the effect of different bone properties to micromotion at the interfaces and stress at the implant. Another objective of this study is to clarify either the simplification of bone properties could be make in order to analyse the micromotion at the interfaces and stress distribution at implant.

\section{Stress at component}

Model 1 experienced the lowest von Mises stress as compared with another two models with cancellous bone. The von Mises stress at implant for model 3 was $80 \%$ higher in C load, and $10 \%$ higher in SA load as compared to implant for model 2. While, the percentage was even higher if model 3 was compared to model 1, where for C and SA load, the stress was high up to $126 \%$ and $32 \%$, respectively. However, during SP load, model 2 had highest maximum stress $(21 \mathrm{MPa})$ at implant if compared to model 1 and model 3, which have almost similar maximum stress at implant, $17 \mathrm{MPa}$. The maximum stress as well as time for analysis for three different models in three different load location were shown in Table 2.
Table 1 Material properties for three different models

\begin{tabular}{lllll}
\hline Load & & C & SA & SP \\
\hline $\begin{array}{l}\text { Model 1 } \\
\text { (full cortical) }\end{array}$ & $\sigma_{\max }(\mathrm{MPa})$ & 4.27 & 18.23 & 17.63 \\
& Time & $2 \mathrm{~h} 42 \mathrm{~m}$ & $1 \mathrm{~h} 51 \mathrm{~m}$ & $2 \mathrm{~h} 7 \mathrm{~m}$ \\
$\begin{array}{l}\text { Model 2 } \\
\text { (Isotropic) }\end{array}$ & $\sigma_{\max }(\mathrm{MPa})$ & 5.37 & 21.74 & 20.97 \\
& Time & $2 \mathrm{~h} 42 \mathrm{~m}$ & $2 \mathrm{~h} 53 \mathrm{~m}$ & $3 \mathrm{~h} 6 \mathrm{~m}$ \\
$\begin{array}{l}\text { Model 3 } \\
\text { (Orthotropic) }\end{array}$ & $\sigma_{\max }(\mathrm{MPa})$ & 9.23 & 23.37 & 17.06 \\
& Time & $4 \mathrm{~h} 20 \mathrm{~m}$ & $3 \mathrm{~h} 12 \mathrm{~m}$ & $6 \mathrm{~h} 8 \mathrm{~m}$ \\
\hline
\end{tabular}

Figure 3 showed the stress distribution at implant for three different bone properties in three load cases. Based on the results, the maximum stresses at implant were associated with the load applied, where for centre load, the maximum stress located surround the central peg, whilst, for SA and SP load, the maximum stresses were located at the back side of implant at superior-anterior and superior-posterior, respectively. The stress at implant was associated with glenoid component loosening especially during eccentric loading (SA and SP load). Results from this study in all models were in agreement with previous literatures, where the eccentric load can increase the stress at the edge of the implant(P. Mansat et al., 2007; J. Zhang et al., 2013). However, large different percentage, which is up to $110 \%$, give a sign where any simplification of bone properties could not be made, otherwise, it would lead to wrong results interpretation. For instance, lower stress produced in model 1 showing that there was no indication of implant loosening, however, in model 3, stress at the implant achieving the yield stress during SA and SP load. This can be confirmed that the implant might lead to implant loosening.

\section{Solid Isotropic Orthotropic}
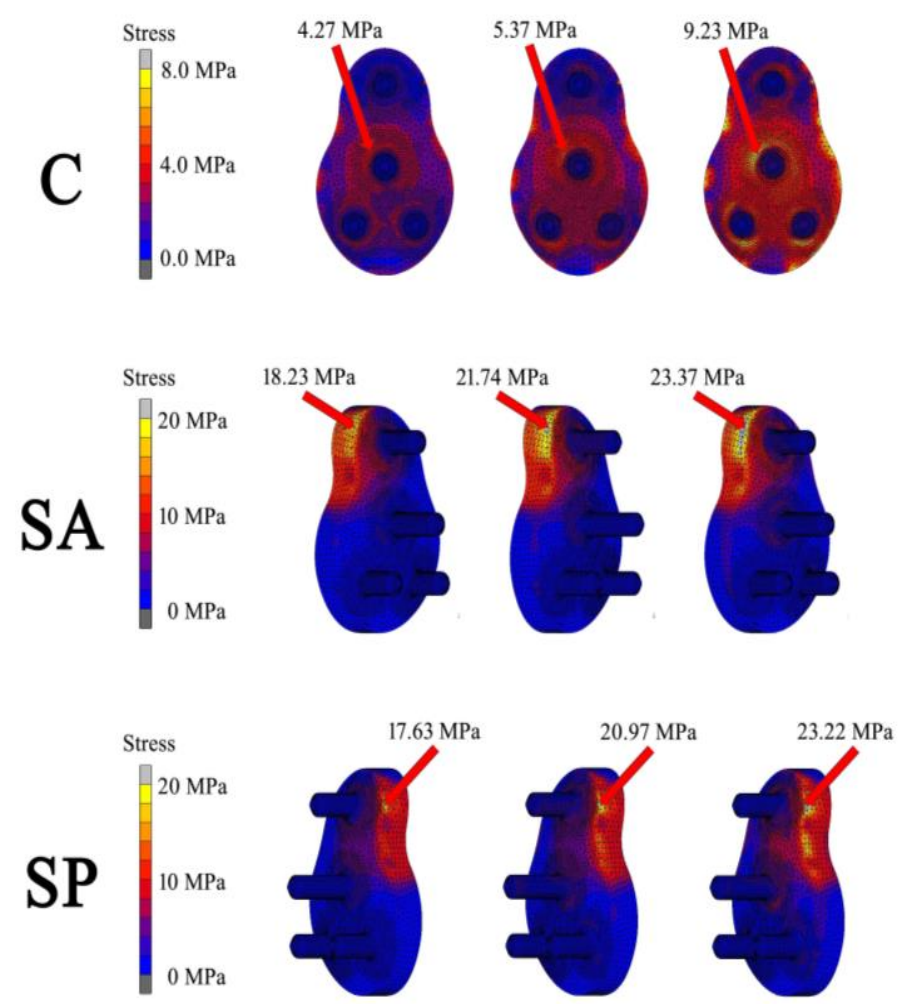

Fig. 4 Stress distribution at the implant for three models in three different load location 


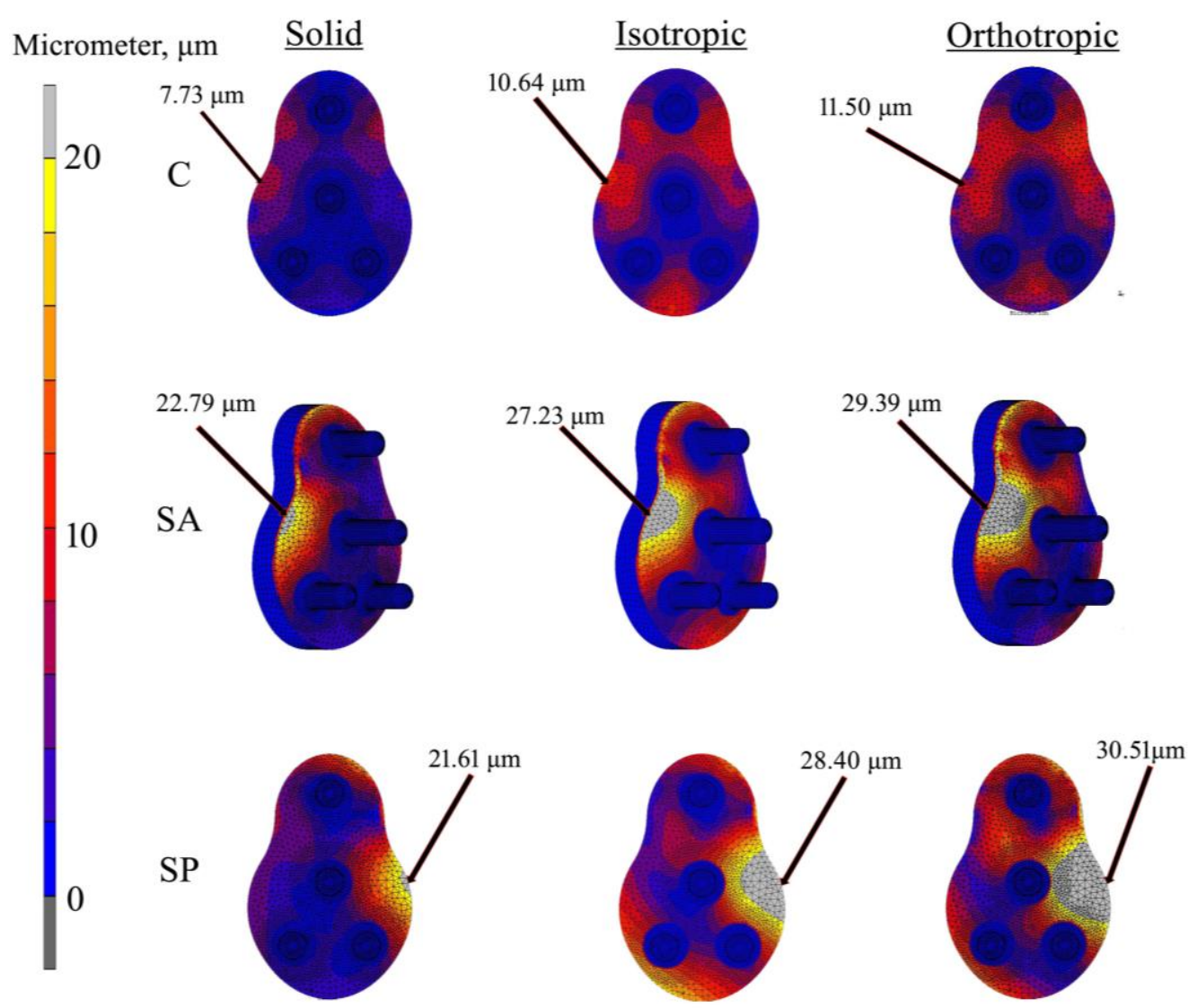

Figure 5 Contour plot of micromotion at implant-bone interface

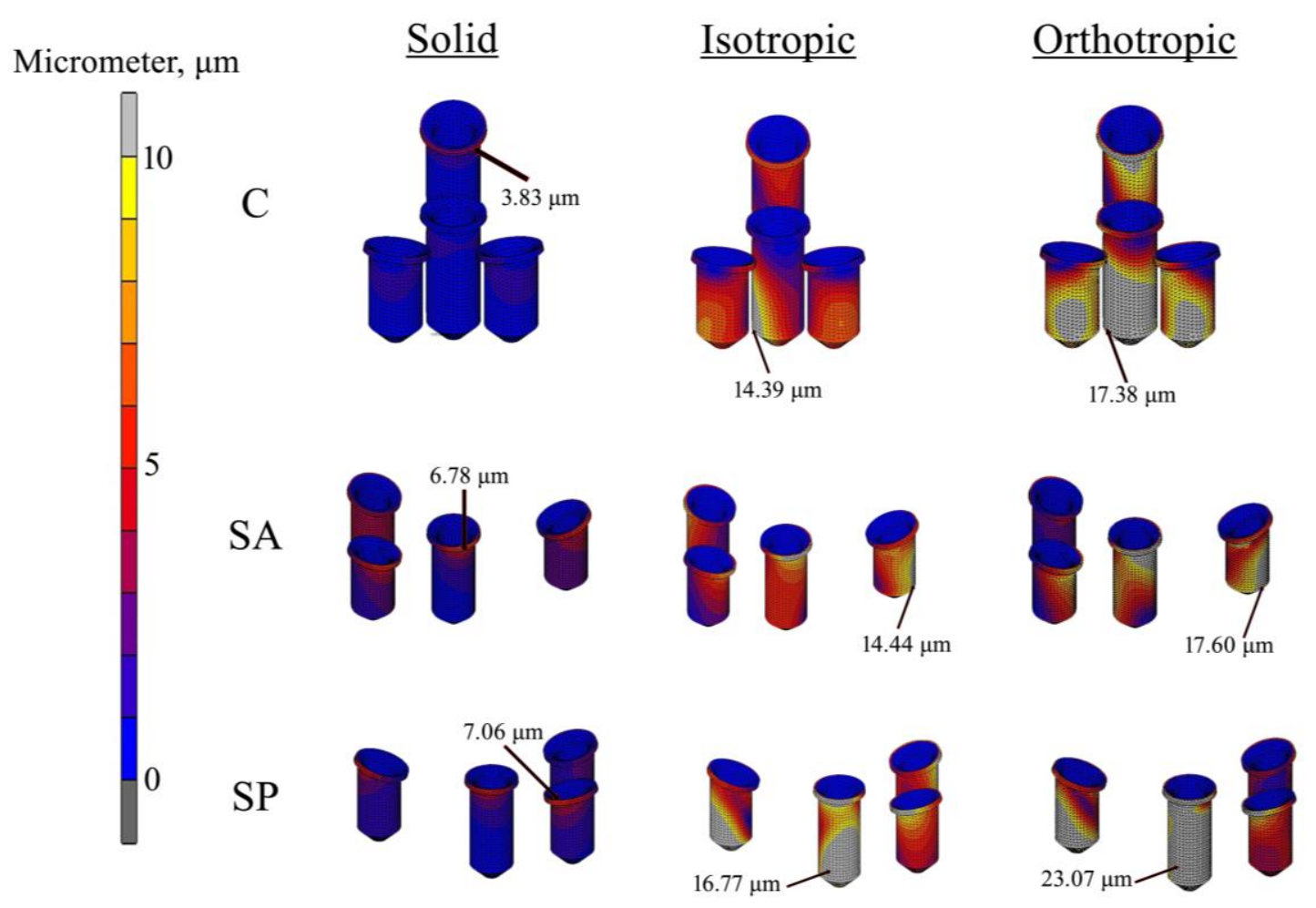

Figure 6 Contour plot of micromotion at cement-bone interface 


\section{Micromotion at interfaces}

Another parameters which highly related to glenoid implant loosening are micromotion at the bone-cement interface (Terrier et al., 2005) and bone-implant interface (Sarah et al., 2010). From the results, micromotion at the implant-bone interfaces showed the same trend where model 1 had lowest values and model 3 had highest values for micromotion, while, micromotion for model 2 was in between model 1 and model 3. However, the different for micromotion at the implantbone interfaces was smaller if compared to different at cement-bone interface. Model 3 had an average $40 \%$ higher compared to model 1 , while different between model 3 and model 2 was less than $10 \%$. Figure 4 showed micromotion at implant-bone interface for three different bone models. Likewise, micromotion at the cement-bone interface showed that model 1 had small micromotion values as compared to another two heterogenous models, model 2 and model 3 in all three load conditions. During the $\mathrm{C}$ load, micromotion at the cement-bone interface in model $3(24.73 \mu \mathrm{m})$ demonstrated five times higher compared to model $1(3.83 \mu \mathrm{m})$ and $72 \%$ different was found between model 2 and model 3. Similarly, during eccentric load, micromotion for model 3 was two folds higher during the SA load and three folds higher during the SP load compared with model 1 in both cases. While, different between model 2 and model 3 was $35 \%$ for SA load and $59 \%$ for SP load. Figure 5 showed the micromotion at cement-bone interfaces for three different models at three different load conditions.

Assuming glenoid bone model as a full cortical lead to inaccuracy of micromotion measurement as the result showed it had very low micromotion in model 1 . On the other hand, the micromotion was higher in bone with cancellous compared to full cortical, model 1. It was due to stiffer bone, which not mimicking real bone, surrounding the cement in model 1, prevent the cement motion. Additionally, the different in micromotion for model 2 and model 3 was due to different modulus definition for both models. For orthotropic properties, the modulus were differs for each axis ( $x$-axis $\neq y$-axis $\neq z$-axis $)$ while, isotropic only had one modulus which same for all axis ( $\mathrm{x}$-axis $=\mathrm{y}$-axis $=\mathrm{z}$-axis). Furthermore, the result from this study showed that peak micromotion at bone-cement interface was differ between model 1 and another two, where in model 1, peak micromotion occurs at the tip of the cement for all three load conditions. While, for model 2 and model 3 , peak micromotion occurs at the bottom side of the cement, where the cement touch the cancellous bone. It was in an agreement with the theory where the displacement was influence by modulus of the material as stated in Eq. (1).

$$
\delta=\frac{P L}{A E}
$$

Where, $\delta$ was a displacement at one point relative to another point, $\mathrm{P}$ was pressure applied, $\mathrm{L}$ was distance between points, A represent cross sectional area, and $\mathrm{E}$ was modulus of elasticity for the material.

\section{Stress Critical Volume (SCV) of the cement}

Another factors which accelerating the occurrence of glenoid component loosening was osteolysis, which occurs due to existence of cement debris (Topoleski, Ducheyne, \& Cuckler, 1990). This debris resulting from cement micro-cracks due to high stress at the cement. It would triggered the immune systems to react with the debris to start protection reaction. This protection reaction then cause tissue breakdown as cell-cell interactions start to attract macrophages that contribute to tissue reabsorption and by-products of tissue inflammation. Later, the empty space created tends to allow greater motion, consequently, it lowered the integrity of its attachment at bonecement interface (Purdue et al., 2006; Topoleski et al., 1990). Therefore, several studies was conducted for predicting the cement failure, where a relationship between probability of survival to failure for hand mixed cement and maximum principal stress for 10 million cycles was obtained by Murphy and Prendergast (Murphy \& Prendergast, 2000). Based on their theory, $5 \mathrm{MPa}$ stress at the cement result in cement survival probability after 10 million cycles lower than $65 \%$. While, in another experimental study by Davies et al. (Davies et al., 1988), they reported that Weibull fatigue life for cement stress at 7 MPa could survive till 245,000 cycles, while, for 15 MPa cement stress could withstand 1,600 cycles. According to this experimental studies, 5 $\mathrm{MPa}-7 \mathrm{MPa}$ become as an accepted value to indicate the initiation of cement micro-cracks, which would induce cement debris (Lacroix et al., 2000; Terrier et al., 2005). Finding for SCV at the cement from this study showed that, the different between Model 1 and Model 2 was relatively small. However, Model 3 records higher amount of cement volume, $0.524 \mathrm{~mm}^{3}$, as compared to Model 1 and Model 2 during $\mathrm{C}$ load. In addition, the percentage of SCV at the cement for Model 3 increased up to $62 \%$ and $31 \%$ than another two models (Model 1 and Model 2) when the implant loaded with SA and SP load, respectively. Figure 6 showed the SCV for all three load locations when assigning different properties for cancellous bone.

Higher stress at the implant and cement in orthotropic could be explained by understanding the concept of stress shielding. Basically, stress shielding refers to stress transfer to the metal implant instead of the bone surrounding it due to great different of stiffness between two components. However, it also occurs at the cement-bone interfaces which have a significant higher stiffness compared to surrounding cancellous bone (Q.-H. Zhang et al., 2016). This might induce bone resorption which could make bone surround implant become weaker and, later, fracture (Huiskes et al.,1992). More flexible implant could reduce the effect of stress shielding, unfortunately, it induced stress at the bone interfaces which could lead to implant loosening due to micromotion (Huiskes et al., 1992). In order to proof further, pattern of load transferred to each component after total shoulder arthroplasty had been studied by Patel et al (Patel et al., 2014). They reported that, in intact glenohumeral joint, most of the load was carried by cancellous bone, however, after glenoid implant was introduced, the percentage of load transferred to cancellous bone decreased to $60 \%$, while, cement carried about $24 \%$. The reduction in load transferred to bone even higher when metal-back implant was introduced, where, the bone carried only $42 \%$ of stress and metal-backed implant had $57 \%$. Interestingly, once the load applied at beyond peg region of cemented implant, where the implant was supported more by cortical bone, load carried by cement and implant gradually decreased and it was transferred back to cortical bone, which stiffer than cement and implant (Patel et al., 2014). This indicate that the load are more likely to be carried by stiffer region instead of softer region.

\section{STRESS CRITICAL VOLUME}

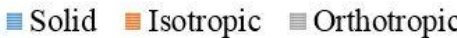

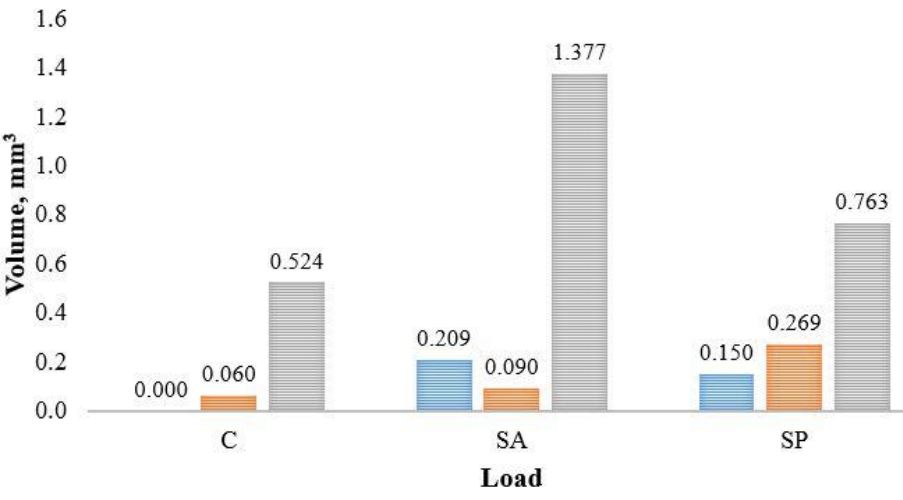

Figure $7 \mathrm{SCV}$ at the cement when changing the material properties of bone in three different load locations

In terms of time consuming for analysing the models, model 1 was found to have less time for analysis (average time was two hours) than model 2 (three hours) and model 3 (four and half hours). Large different between three models, which is more than $10 \%$, was not acceptable for finite element analysis for biological structure (Baca et al., 2008) and prevent from any simplification of bone model could be made. As a result, orthotropic material properties become as a favourite to 
represent the cancellous bone at scapula. Even, the time taken for analysing was double compared to model 1 and model 2, however, it still within acceptable time for analysis and the accuracy of the results would be prioritize in order to mimics the real case. Current study had several limitation to be noted, first, the current study was a fully simulation, nevertheless, this simulated analysis using orthotropic properties can be defined and represented as an actual bone behaviour, since this orthotropic properties was obtained from previous experimental study (Couteau et al., 2001; Pierre Mansat et al., 1998) which used real scapula bone. Therefore, the results obtain from the analysis could avoid from underestimate or overestimate the data in order to predict the glenoid component loosening. Second, glenoid implant had been simulated without humeral head, which can affected to load distribution. However, the load contact area for eccentric load (SA and SP load) was located at $10^{\circ}$ to the anterior and posterior of glenoid surface and $20^{\circ}$ to superior of glenoid surface (Stone et al., 1999). Thirdly, this study evaluate the bone as homogenous which in reality, the bone was inhomogenous. Thus, future studies should consider this aspect for simulating better clinical scenarios and result in more accurate results.

\section{CONCLUSION}

This study successfully simulated three models of scapula with different bone properties, which fixated with a glenoid implant via finite element method. It can be concluded that different properties of cancellous bone affected the micromotion at the interfaces and stress distribution at implant that could lead to improper prediction of glenoid component performance. Furthermore, this study also found that the orthotropic behaviour is more favourable option to mimic real condition of bone and allowed more reliable prediction on glenoid component loosening.

\section{ACKNOWLEDGEMENT}

No funding was received to support this study. Access to the CT images of the right upper limb used in this study was granted by the Chairman of Clinical Research Centre, Hospital Tengku Ampuan Afzan, 25100 Kuantan, Pahang Darul Makmur, Malaysia. All procedures performed in studies involving human participants were in accordance with the ethical standards of the institutional and/or national research committee and with the 1964 Helsinki declaration and its later amendments or comparable ethical standards.

\section{REFERENCES}

Abdul Wahab, A. H., Abdul Kadir, M. R., Kamarul, T., Harun, M. N., Syahrom, A. (2016). Analysis on stress and micromotion on various peg fixation at glenoid implant. Tribology - Materials, Surfaces \& Interfaces, 10(1), 2632 .

Allred, J. J., Flores-Hernandez, C., Hoenecke Jr, H. R., D'Lima, D. D. (2016) Posterior augmented glenoid implants require less bone removal and generate lower stresses: a finite element analysis. Journal of Shoulder and Elbow Surgery, 25(5), 823-830.

Anglin, C., Wyss, U. P., Nyffeler, R. W., Gerber, C. (2001). Loosening performance of cemented glenoid prosthesis design pairs. Clinical Biomechanics, 16(2), 144-150.

Armstrong, A. D. L. G. S. (2013). Design Evolution of the glenoid component in total shoulder arthroplasty. JBJS Reviews, 1(2).

Baca, V., Horak, Z., Mikulenka, P., Dzupa, V. (2008). Comparison of an inhomogeneous orthotropic and isotropic material models used for FE analyses. Medical Engineering \& Physics, 30(7), 924-930.

Bohsali, K. I., Wirth, M. A., Rockwood, C. A., Jr. (2006). Complications of total shoulder arthroplasty. Journal of Bone Joint Surgery, 88(10), 2279-2292.

Couteau, B., Mansat, P., Estivalèzes, É., Darmana, R., Mansat, M., Egan, J. (2001). Finite element analysis of the mechanical behavior of a scapula implanted with a glenoid prosthesis. Clinical Biomechanics, 16(7), 566575.

Davies, J. P., O'Connor, D. O., Burke, D. W., Jasty, M., Harris, W. H. (1988) The effect of centrifugation on the fatigue life of bone cement in the presence of surface irregularities. Clinical Orthopaedics and Related Research (229), 156-161.
Geraldes, D. M., Hansen, U., Jeffers, J., Amis, A. A. (2017). Stability of small pegs for cementless implant fixation. Journal of Orthopaedic Research.

Geraldes, D. M., Phillips, A. T. M. (2014). A comparative study of orthotropic and isotropic bone adaptation in the femur. International Journal for Numerical Methods in Biomedical Engineering, 30(9), 873-889.

Gonzalez, J. -F., Alami, G. B., Baque, F., Walch, G., Boileau, P. (2011). Complications of unconstrained shoulder prostheses. Journal of Shoulder and Elbow Surgery, 20(4), 666-682.

Gupta, S., Van der Helm, F. C. T., Van Keulen, F. (2004). Stress analysis of cemented glenoid prostheses in Total Shoulder Arthroplasty. Journal of Biomechanics, 37(11), 1777-1786.

Huiskes, R., Weinans, H., Van Rietbergen, B. (1992). The relationship between stress shielding and bone resorption around total hip stems and the effects of flexible materials. Clinical Orthopaedics and Related Research, 274, 124-134.

Jones, R. B. (2013). Addressing glenoid erosion in anatomic total shoulder arthroplasty. Bulletin of the Hospital for Joint Disease (2013), 71 Suppl 2, S46-50.

Lacroix, D., Murphy, L. A., Prendergast, P. J. (2000). Three-dimensional finite element analysis of glenoid replacement prostheses: a comparison of keeled and pegged anchorage systems. Journal of Biomechanical Engineering, 122(4), 430-436.

Mansat, P., Barea, C., Hobatho, M.-C., Darmana, R., Mansat, M. (1998). Anatomic variation of the mechanical properties of the glenoid. Journal of Shoulder and Elbow Surgery, 7(2), 109-115.

Mansat, P., Briot, J., Mansat, M., Swider, P. (2007). Evaluation of the glenoid implant survival using a biomechanical finite element analysis: Influence of the implant design, bone properties, and loading location. Journal of Shoulder and Elbow Surgery, 16(3, Supplement), S79-S83.

Matsen, F. A., 3rd, Clinton, J., Lynch, J., Bertelsen, A., Richardson, M. L. (2008). Glenoid component failure in total shoulder arthroplasty. Journal of Bone and Joint Surgery, 90(4), 885-896.

Miller, Z., Fuchs, M. B., Arcan, M. (2002). Trabecular bone adaptation with an orthotropic material model. Journal of Biomechanics, 35(2), 247-256.

Murphy, B. P., Prendergast, P. J. (2000). On the magnitude and variability of the fatigue strength of acrylic bone cement. International Journal of Fatigue, 22(10), 855-864.

Patel, R. J., Wright, T. M., Gao, Y. (2014). Load transfer after cemented total shoulder arthroplasty. Journal of Shoulder and Elbow Surgery, 23(10), 1553-1562.

Purdue, P. E., Koulouvaris, P., Nestor, B. J., Sculco, T. P. (2006). The central role of wear debris in periprosthetic Osteolysis. Musculoskeletal Journal of Hospital for Special Surgery, 2(2), 102-113.

Rodosky, M. W., Bigliani, L. U. (1996). Indications for glenoid resurfacing in shoulder arthroplasty. Journal of Shoulder and Elbow Surgery, 5(3), 231248.

Sarah, J., Sanjay, G., Sanjay, S., Carolyn, A., Emery, R., Andrew, A., Ulrich, H. (2010). Failure mechanism of the all-polyethylene glenoid implant. Journal of Biomechanics, 43(4), 714-719.

Stone, K. D., Grabowski, J. J., Cofield, R. H., Morrey, B. F., An, K. N. (1999). Stress analyses of glenoid components in total shoulder arthroplasty. Journal of Shoulder and Elbow Surgery, 8(2), 151-158.

Terrier, A., Büchler, P., Farron, A. (2005). Bone-cement interface of the glenoid component: Stress analysis for varying cement thickness. Clinical Biomechanics, 20(7), 710-717.

Topoleski, L. D., Ducheyne, P., Cuckler, J. M. (1990). A fractographic analysis of in vivo poly(methyl methacrylate) bone cement failure mechanisms. Journal of Biomedical Materials Research, 24(2), 135-154.

Wahab, A. H. A., Kadir, M. R. A., Harun, M. N., Kamarul, T., Syahrom, A. (2017). Number of pegs influence focal stress distributions and micromotion in glenoid implants: a finite element study. Medical \& Biological Engineering \& Computing, 55(3), 439-447.

Wirtz, D. C., Pandorf, T., Portheine, F., Radermacher, K., Schiffers, N., Prescher, A., . . . Niethard, F. U. (2003). Concept and development of an orthotropic FE model of the proximal femur. Journal of Biomechanics, 36(2), 289-293.

Yongpravat, C., Kim, H. M., Gardner, T. R., Bigliani, L. U., Levine, W. N., Ahmad, C. S. (2013). Glenoid implant orientation and cement failure in total shoulder arthroplasty: a finite element analysis. Journal of Shoulder and Elbow Surgery, 22(7), 940-947.

Zhang, J., Yongpravat, C., Kim, H. M., Levine, W. N., Bigliani, L. U., Gardner, T. R., Ahmad, C. S. (2013). Glenoid articular conformity affects stress distributions in total shoulder arthroplasty. Journal of Shoulder and Elbow Surgery, 22(3), 350-356.

Zhang, Q.-H., Cossey, A., Tong, J. (2016). Stress shielding in bone of a bonecement interface. Medical Engineering \& Physics, 38(4), 423-426. 